|| Print ISSN: 2589-7837 || Online ISSN: 2581-3935 ||

International Journal of Medical Science and Diagnosis Research (IJMSDR)

Available Online at www.ijmsdr.com

NLM (National Library of Medicine ID: 101738824)

Original Research Article

Volume 5, Issue 2; February: 2021; Page No. 06-11

\title{
KNOWLEDGE, ATTITUDE AND PRACTICES AMONG NURSES TOWARDS HIV/ AIDS PATIENTS IN TERTIARY CARE HOSPITAL, AMROHA
}

\author{
Atul Agrawal $^{1}$, Ankita Agrawal ${ }^{2}$ \\ ${ }^{1}$ Associate Professor, Department of Community Medicine, VIMS, Amroha \\ ${ }^{2}$ Physiotherapist, Department of Physiotherapy, MSR Medical College, Bengaluru
}

Conflicts of Interest: Nil

Corresponding author: Atul Agrawal

DOI: https://doi.org/10.32553/ijmsdr.v5i2.755

\begin{abstract}
:
Background: Human Immunodeficiency Virus (HIV) has become one of the most serious challenges to public health due to its high morbidity, mortality and economic impacts. Good Knowledge, positive attitudes and practices are important aspects of providing nursing care for people living with HIV/AIDS. Aim: This study aimed to assess knowledge, attitudes and practices of nurses working with HIV/AIDS patients. Methods: This study was descriptive, performed on 200 nurses working with HIV/AIDS patients at a tertiary care Hospital, Amroha. Data was collected using pretested, validated, self administered questionnaire consisting of knowledge, attitude and practice based questions related to HIV/Aids and infected patients along with demographic variables of nursing staff under study. Results: The result of this study showed that majority of nurses (81\%) working with HIV/AIDS patients possess adequate level of knowledge. Most of the nurses under study showed high level of empathic attitude toward people living with HIV/AIDS (above 80\%) but at the same time high level of avoidance was observed among some nurses. Practice of nurses working with HIV/AIDS patients was found good. Conclusions: There was satisfactory knowledge, positive attitudes and good practice level among nurses under study. Recommendations: Training should focus on Preventive methods and modes of HIV transmission, care and support of all patients no matter what the disease, emphasizing confidentiality as a patient right that should not be ignored and should train nurses and monitor nursing skills.
\end{abstract}

Keywords: Public health, Nurses, HIV, Knowledge, Attitude, Practices

\section{Introduction:}

HIV positive patients access to Hospital with an aim to receive proper treatment and care. Nursing staff in a hospital plays an important role in providing treatment and care to these HIV patients. Nurses perform a variety of roles such as caregiver, communicator, teacher, counselor, leader, change agent, manager, and research consumer in Hospitals. They may be carried out simultaneously depending on the need of the subject in a particular situation and case. As a caregiver, nurses are expected to assist the convalescent's physical, psychological, developmental, cultural, and spiritual needs to attain the utmost possible level of health and wellness. The duties of Nurses include collecting body samples such as blood samples, sputum samples, urine samples, stool samples, other body fluids, cleaning and changing beds along with administering intravenous, intramuscular and oral medications. Ineffective sterilization technique, inappropriate disposal of used syringes, needles, poor sanitation and use of inadequate precautions while nursing HIV patients increases the hazards of getting HIV infected. The transmission rate of HIV per exposure is less than $0.5 \%$ and contributes to $0.01 \%$ of global infections.

It has widely been observed that people infected with HIV frequently encounter discrimination while seeking and receiving health care services. The lack of universal adherence to infection control protocols such as Injection safety possess a great risk for nurses of occupational HIV infection at virtually every level of their daily work. Due to the risk of getting infected while handling and nursing HIV patients, it has been observed sometimes that nurses discriminate and avoid treating HIV patients.

The lack of vaccine or cure for HIV/ Aids makes information, education, training and communication the only measure to prevent infection. It is essential for nurses to have proper updated knowledge about HIV transmission, prevention and treatment so as to maintain quality of care while encountering clinical exposure to increasing HIV patients in hospitals. It has become very important to effectively tackle the stigma attached to this disease amongst nursing staff. Better knowledge, attitude and practices of Nursing staff is expected to improve the anxiety 
about treating HIV patients and also improve patient compliance with standard treatment to patients. Knowledge about basic infection control measures can reduce the risk of HIV associated health care infections in Nurses. Considering these factors and with an aim to improve the quality of Health care services provided by Nurses, Knowledge, attitude and practices study of Nurses regarding HIV was conducted in tertiary care hospital in Amroha.

\section{Aims and Objectives}

1. To assess the knowledge of nurses regarding HIV/AIDS

2. To assess the attitude \& practices of nurses towards care of HIV/AIDS patients

\section{Methodology}

A descriptive cross sectional study was conducted over a period of 2 months at tertiary care hospital in Amroha amongst nursing staff of the Hospital. Study was carried out from 5th January 2020 to 5th March 2020. Nurses working in General Medicine, Obstretics and Gynecology, Surgery, Pulmonary Medicine and Casualty were included. The selection of study subjects was done using convenient sampling technique from amongst those nurses present at the time of study. Those nurses who were not willing to participate in the study were excluded from the study. A written informed consent was obtained from the Nurses after properly explaining them about objectives of the study. The data was collected by using a pretested, validated, self administered questionare consisting of 30 questions for assessment of Knowledge, attitude and practices of nurses regarding HIV patients (10 questions for each) other than demographic details of study subjects. The questionare was pilot tested among 4 senior Nursing staff members with respect to its clarity, comprehensibility and cultural appropriateness to this institutional setup. The questionnaire was divided into 4 main sections and the information required was collected under following categories:

1) Demographic variables of Nursing staff in the Hospital

2) Knowledge about HIV with special consideration given to its spread, mode of transmission, safety measures and universal precautions to be used and post exposure prophylaxis

3) Attitude of Nurses towards HIV positive patients

4) Practices of Nurses while handling \& nursing HIV/AIDS patients

Knowledge assessement of the study subjects was done with a pretested questionnaire containing 10 questions as mentioned above in which on the basis of the number of correct answers given, their knowledge was classified into Adequate (6-10 correct answers) and Inadequate (0-5 correct answers).

Attitude assessement of the study subjects was done with a pretested questionnaire containing 10 questions in which answer found satisfactory as per expectations and promoting proper health care of HIV/AIDS patients was given 1 point and further, their attitude was classified into Positive (6-10 expected answers) and Negative(0-5 expected answers) on the basis of number of satisfactory answers given by study subjects.

Similarly, assessement of practices of study subjects was done with a pretested questionnaire containing 10 questions in which answer found satisfactory as per expectations and promoting proper health care of HIV/AIDS patients was given 1 point and further, practices were classified into Good (6-10 expected answers) and Poor (0-5 expected answers) on the basis of number of satisfactory answers given by study subjects.

\section{Results}

200 study subjects who gave consent for the study were selected and they answered to the questionnaire. Most of the study subjects were of the age group of 21-40 yrs (61\%). The mean age of the study participants was $26 \mathrm{yrs}(\mathrm{N}=$ 200). A majority of study subjects were females (86\%). Amongst the study subjects, $71 \%$ were married. The qualification of the study subjects in the study were B.Sc Nursing(42\%), Diploma Nursing(22\%) and GNM (General Nursing and Midwifery-36\%). Most of the study subjects were Senior Nurses which included 74\% nurses working for $\leq 5 \mathrm{yrs}, 14 \%$ nurses working for 6-10 yrs, $12 \%$ nurses working since 11 or more years.

Table 1:

\begin{tabular}{lll}
\hline Variables & & $\mathbf{N}(\mathbf{\%})$ \\
\hline \multirow{2}{*}{ Age } & $21-40$ yrs & $132(66 \%)$ \\
\cline { 2 - 3 } & $41-60$ yrs & $68(34 \%)$ \\
\hline \multirow{2}{*}{ Gender } & Male & $28(14 \%)$ \\
\cline { 2 - 3 } & Female & $172(86 \%)$ \\
\cline { 2 - 3 } & Married & $142(71 \%)$ \\
\cline { 2 - 3 } & Unmarried & $22(11 \%)$ \\
\cline { 2 - 3 } & Divorced & $36(18 \%)$ \\
\cline { 2 - 3 } & Diploma Nursing & $44(22 \%)$ \\
\cline { 2 - 3 } & GNM & $72(36 \%)$ \\
\hline Work Experience & $\leq 5$ years & $84(42 \%)$ \\
\cline { 2 - 3 } & 6-10 years & $28(148(74 \%)$ \\
\cline { 2 - 2 } & $\geq 11$ years & $24(12 \%)$ \\
\hline
\end{tabular}


Table 2: Responses of nurses to HIV related knowledge questions. ( Total subjects in the study: $\mathrm{N}=200$ )

\begin{tabular}{lllll}
\hline $\begin{array}{l}\text { Sr. } \\
\text { No. }\end{array}$ & Questions & Yes & No & $\begin{array}{l}\text { Don't } \\
\text { Know }\end{array}$ \\
\hline K1 & HIV/AIDS can be prevented by use of safe injection practices. & $178(89 \%)$ & $20(10 \%)$ & $2(1 \%)$ \\
\hline K2 & HIV/AIDS is transmitted through Coughing / Sneezing. & $18(9 \%)$ & $156(78 \%)$ & $26(13 \%)$ \\
\hline K3 & HIV/AIDS is transmitted through Flies. & $6(3 \%)$ & $166(83 \%)$ & $28(14 \%)$ \\
\hline K4 & Is there any difference between HIV and AIDS? & $132(66 \%)$ & $54(27 \%)$ & $14(7 \%)$ \\
\hline K5 & HIV/AIDS transmission can be prevented by use of condom & $198(99 \%)$ & $2(1 \%)$ & 0 \\
\hline K6 & HIV/AIDS can be completely cured & $24(12 \%)$ & $156(78 \%)$ & $20(10 \%)$ \\
\hline K7 & It is necessary to use universal precautions while handling HIV/AIDS & $200(100 \%)$ & 0 & 0 \\
& patients & & & \\
\hline K8 & Can HIV/AIDS be transmitted by unprotected Sex? & $186(93 \%)$ & $4(2 \%)$ & $10(5 \%)$ \\
\hline K9 & Vaccine is available for prevention of HIV/AIDS & $4(2 \%)$ & $154(77 \%)$ & $42(21 \%)$ \\
\hline K10 & HIV is transmitted by eating together & $4(2 \%)$ & $194(97 \%)$ & $2(1 \%)$ \\
\hline
\end{tabular}

Table 3: Responses of nurses to HIV related attitude questions. (Total subjects in the study: $\mathrm{N}=200$ )

\begin{tabular}{llll}
\hline $\begin{array}{l}\text { Sr. } \\
\text { No. }\end{array}$ & Question & YES & NO \\
\hline A1 & $\begin{array}{l}\text { HIV/AIDS patients should be isolated and kept in separate ward after admission in } \\
\text { hospital. }\end{array}$ & $182(91 \%)$ & $18(9)$ \\
\hline A2 & Should HIV/AIDS patients be treated in a friendly manner and with sympathetic attitude? & $186(93 \%)$ & $14(7 \%)$ \\
\hline A3 & Are you afraid of treating HIV Positive patients? & $8(4 \%)$ & $192(96 \%)$ \\
\hline A4 & All patients should be investigated for HIV before admission and treatment? & $196(98 \%)$ & $4(2 \%)$ \\
\hline A5 & HIV patients get diseased because of the curse of God / or their own wrong deeds. & $12(6 \%)$ & $188(94 \%)$ \\
\hline A6 & $\begin{array}{l}\text { Do you think that special training programs for nurses to handle HIV patients be } \\
\text { organized? }\end{array}$ & $178(89 \%)$ & $22(11 \%)$ \\
\hline A7 & Do you wish to assist the delivery of HIV positive mothers? & $20(10 \%)$ & $180(90 \%)$ \\
\hline A8 & $\begin{array}{l}\text { All patients with HIV/AIDS are entitled to confidentiality, even if it puts other people at } \\
\text { risk of contracting the disease. }\end{array}$ & $6(3 \%)$ & $194(97 \%)$ \\
\hline A9 & Patients with HIV/AIDS have the right to the same quality of care as any other patient & $164(82 \%)$ & $36(18 \%)$ \\
\hline A10 & $\begin{array}{l}\text { Do you think that you should worry about putting your family and friends at risk of } \\
\text { contracting the disease while caring for a HIV/AIDS patient? }\end{array}$ & $12(6 \%)$ & $188(94 \%)$ \\
\hline
\end{tabular}

Table 4: Responses of nurses to HIV related Practice questions. ( Total subjects in the study: N=200)

\begin{tabular}{llll}
\hline $\begin{array}{l}\text { Sr. } \\
\text { No. }\end{array}$ & Questions & Yes & No \\
\hline P1 & Do you use gloves while handling HIV patients? & $184(92 \%)$ & $16(8 \%)$ \\
\hline P2 & Do you bend/ break needles after using? & $196(98 \%)$ & $4(2 \%)$ \\
\hline P3 & Do you avoid leaving open syringes? & $200(100 \%)$ & 0 \\
\hline P4 & Do you use separate containers to dispose used syringes? & $172(86 \%)$ & $28(14 \%)$ \\
\hline P5 & Do you encourage people to get tested and counseled for HIV/AIDS? & $162(81 \%)$ & $38(19 \%)$ \\
\hline P6 & Did you ever consider starting PEP after an occupationally acquired needle stick injury & $166(83 \%)$ & $34(17 \%)$ \\
\hline P7 & Do you recap needles immediately after using them? & $176(88 \%)$ & $24(12 \%)$ \\
\hline P8 & Do you practice universal blood and body fluid precautions at your workplace? & $164(82 \%)$ & $36(18 \%)$ \\
\hline P9 & Do you wash your hands before examining a patient? & $188(94 \%)$ & $12(6 \%)$ \\
\hline P10 & $\begin{array}{l}\text { Do you treat blood spills on floors or other surfaces with a disinfectant before cleaning } \\
\text { up? }\end{array}$ & $160(80 \%)$ & $40(20 \%)$ \\
\hline
\end{tabular}




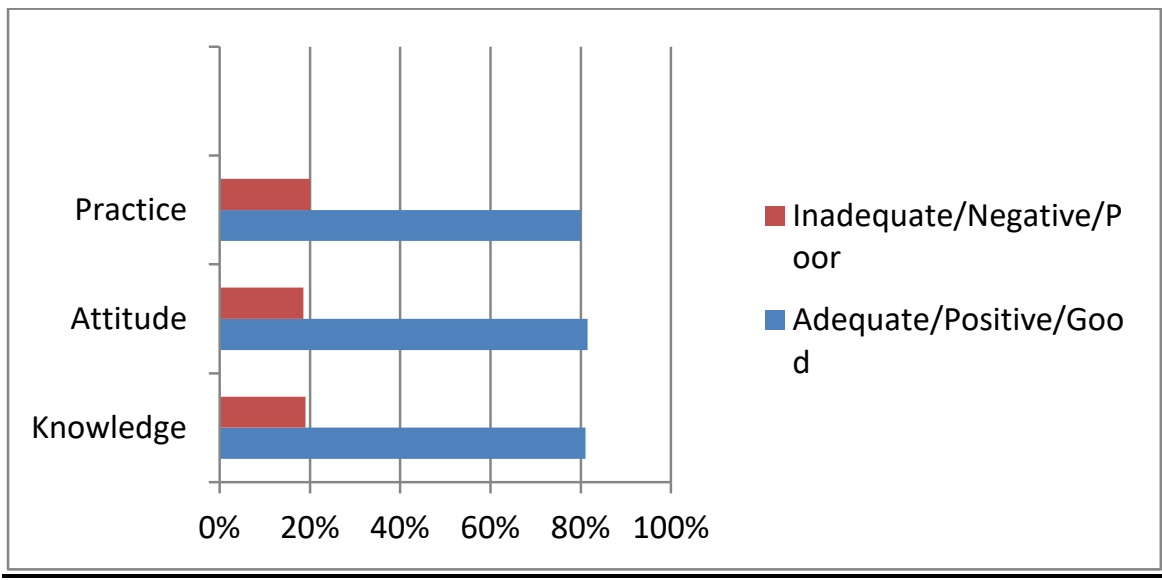

\section{Discussion:}

Most of the study subjects were Females (86\%) which indicates lesser number of Male nurses in the hospital and also demands promotion of interest of Males towards Nursing occupation. Most of the nurses had completed B.Sc nursing $(42 \%), 22 \%$ nurses had done diploma in nursing and $36 \%$ completed GNM course which indicates highly educated nursing staff in the hospital.

The overall knowledge of nurses in this study was found satisfactory, as similar to the findings of similar study conducted by Dorothy et al in Ghana ${ }^{(1)}$, Ambica Reddy et al in Guntur ${ }^{(2)}$ and Harshvardhan et al in Faridkot ${ }^{(5)}$. $89 \%$ of the study subjects knew that HIV/AIDS can be prevented by use of safe injection practices. $78 \%$ of the study subjects knew that HIV is not transmitted through coughing or sneezing. 83\% study subjects knew that HIV is not transmitted through flies. $66 \%$ of the study subjects knew that HIV and AIDS are different. 78\% study subjects knew that complete cure of HIV is not possible. 93\% study subjects knew that HIV/ AIDS can spread due to unprotected sex. All of them thought that universal precautions use is mandatory while handling HIV positive patients. 97\% study subjects were aware of the fact that HIV/AIDS is not transmitted by eating together. $77 \%$ study subjects knew that vaccine is not available for prevention of HIV/AIDS.

However it is a matter of concern that some of the study subjects had no idea about mode of transmission of
HIV/Aids. Almost 27\% of study subjects didn't knew the difference between HIV and AIDS. 12\% incorrectly believed that HIV/Aids can be completely cured. $2 \%$ still incorrectly knew that vaccine is available for prevention of HIV/AIDS. 14\% didn't used separate containers to dispose used syringes. $8 \%$ did not used gloves while handling HIV patients. $2 \%$ study subjects didn't had the habit of breaking needles after use. Such practices if not improved can affect the treatment of HIV patients. It was observed that with an increase in experience of the nursing staff there was a increase in knowledge towards nursing HIV patients in the hospital. Most of the well experienced nurses were found to have a comparatively better knowledge than the newly joined nurses. It was seen that with an increase in experience of nurses, there was a decrease in hesitation to handle HIV positive patients. These nurses play a very important role in care and recovery of HIV/ AIDS patients and these if found having inaccurate knowledge, attitude and practices towards HIV patients, it may adversely affect the treatment provided to patients and also the reputation of the Hospital. Such inaccurate knowledge may also lead to increased prevalence of HIV infection among nursing staff. Surprisingly, $3 \%$ of the respondents believed that HIV could be spread through flies. Studies carried out illustrate similar findings ${ }^{(2,5)}$ as present study and concluded that majority of nursing staff had adequate $(81 \%)$ level of knowledge about HIV and AIDS.

Table 1:

\begin{tabular}{lll}
\hline Level of Knowledge & Frequency & Percentage values \\
\hline Adequate & 162 & 81 \\
\hline Inadequate & 38 & 19 \\
\hline Total & 200 & 100 \\
\hline
\end{tabular}

Table 2:

\begin{tabular}{lll}
\hline Attitude & Frequency & Percentage values \\
\hline Positive & 163 & 81.5 \\
\hline Negative & 37 & 18.5 \\
\hline Total & 200 & 100 \\
\hline
\end{tabular}


96\% study subjects were not afraid of treating HIV patients as they considered as an opportunity to learn and develop more. However $91 \%$ study subjects thought that HIV patients should be kept in isolation in a separate ward. $98 \%$ nurses were of the opinion that all patients should be investigated for HIV before admission and treatment. $60 \%$ study subjects were ready to assist delivery of HIV positive mothers. 93\% study subjects thought that HIV/AIDS patients should be treated in a friendly manner and with sympathetic attitude. 89\% study subjects demanded for training programs for Nursing care of HIV positive patients. Only $3 \%$ study subjects were of the opinion that all patients with HIV/AIDS are entitled to confidentiality, even if it puts other people at risk of contracting the disease whereas remaining 97\% denied it. $6 \%$ study subjects had a perception that HIV patients get diseased because of the curse of God or due to their own wrong deeds. $82 \%$ study subjects were of the view that patients with HIV/AIDS have the right to the same quality of care as any other patient. $6 \%$ study subjects believed that they put their family and friends at risk of contracting HIV while caring for a HIV/AIDS patient. $81.5 \%$ study subjects showed a positive attitude towards nursing HIV patients.

Safety precautions use practice amongst study subjects while handling HIV patients is very important and was assessed with the help of 10 pretested questions. $92 \%$ study subjects used gloves while handling HIV patients. 98\% study subjects had a practice of breaking needles after use in HIV positive patients. None used to leave open syringes. $86 \%$ used separate containers to dispose syringes used for HIV patients. Majority of study subjects (82\%) used to practice universal blood and body fluid precautions at workplace. $80 \%$ of all study subjects were found to have good practices while handling HIV patients.

\section{Conclusions}

The result indicates that majority of nursing staff $(81 \%)$ at tertiary care hospital have adequate knowledge about HIV/AIDS. Nurses in general expressed high levels of empathic attitudes towards people living with HIV/AIDS (Above $80 \%$ ), but at the same time refraining attitudes were also observed among some nurses. A relatively high level of positive attitude towards HIV/ AIDS patients was observed. Practices in tertiary care hospital, Amroha were found good in majority of study subjects. Generally, Nurses, especially females and senior nurses were well versed with desired levels of knowledge, attitude \& practices towards HIV/AIDS infected patients.

\section{Limitations of study}

The current study should be interpreted in light of some limitations. This survey used nursing staff of a private hospital in Amroha. The response rate could have been influenced by the knowledge, attitudes and behaviors of nursing staff of that hospital. Therefore the results of the present study could not be generalized to other groups of nurses. Future studies could include a larger, randomized sample from a more geographically diverse nursing group which may lead to better idea of Knowledge, attitude and practices of Nurses regarding HIV/ AIDS.

\section{Recommendations}

Education can improve the knowledge and alter the attitudes towards people living with HIV/AIDS. Counseling of family members, relatives and friends of diseased persons should be given the topmost priority to prevent stigma and discrimination so that HIV/AIDS patients can live with their rights. The people living with HIV/AIDS should be counseled so that they can live free from stress and anxiety. They should also be strongly motivated to have safer sex practice to avoid spread of infection. Sex partners of the patients also should be educated about prevention of HIV/AIDS. Mass media should be utilized in a big way to alleviate the misconceptions associated with HIV/AIDS. It is therefore important that the topic HIV/AIDS is included in the nursing education and curriculum. Training programs for Nurses working in the hospital should be organized intermittently to ensure health practices of nurses working in the hospital. We want to highlight the potential need to improve the level of knowledge and attitudes among nursing staff towards HIV/AIDS as they have a key role in prevention, care and treatment in their future career as nurses. Through evaluating the knowledge, attitudes and practices towards people living with HIV/AIDS among nursing staff, gaps can be identified as well as areas of importance for training and health care education amongst nursing staff can be promoted as well.

\section{References}

1. Dorothy Serwaa Boakye, Azwihangwisi Helen Mavhandu-Mudzusi. Nurses knowledge, attitudes and practices towards patients with HIV and AIDS in Kumasi, Ghana. International Journal of Africa Nursing Sciences 11 (2019) 100147.

2. Ambica Reddy, Vikram S Bommireddy, Srinivas Pachava, Viswa C Chandu, Suresh C Yaddanapalli, Asha Lodagala. HIV Knowledge, attitude and practices among nursing students in Guntur city. DOI: 10.4103/ JDRNTRUHS.JDRNTRUHS_11_18.2018. Vol 7. Issue 3-pg. no. 162-167.

3. Lalit Prashant Meena, S.K.Pandey, Madhukar Rai, Anju Bharti. Knowledge, attitude and practices KAP study on HIV AIDS among HIV patients, Care givers and general population in north eastern part of India. DOI: 10.5455/IJMSPH.2013.2.36-42.

4. Adhikari K, Gupta N, Koshy AK, Jain VM, Ghimire A, Jnawali K, Paneru DP. Knowledge and attitude towards HIV/AIDS amongst nursing students in Nepal. SAARC J TUBER LUNG DIS HIV/AIDS, 2015; 12(1)

5. Harsh Vardhan Gupta, Vivek Vardhan Gupta, Gurmeet Kaur, Neha Chitkara, Ruku Malik. Knowledge, attitude and practice towards 
Occupational exposure to HIV infection among nursing staff of tertiary care hospital, Faridkot, India. International journal of Contemporary Medical Research 2017; 4(7):1450-1453.

6. A Agrawal, A Saoji, NB Kasturwar. Knowledge among nurses towards HIV/Aids in Tertiary care Hospital, Nagpur, India. IJRTST, ISSN 2277-2812, Vojume 9, Issue 2, 2013, pp 281-284.

7. A Agrawal. HIV awareness among general population in Durg district. IJMSDR 2018. January vol(2), Issue(1), Page no. 31-35.

8. LP Meena, SK Pandey, M Rai, Anju Bharti, Shyam Sunder. Knowledge, attitude and practices (KAP) study on HIV / Aids among HIV patients, care givers and general population in North Eastern part of India. DOI: 10.5455/ijmsph.2013. vol. 2. Issue 1.36-42.

9. Basavaprabhu Achappa, Soundarya Mahalingam, Priyansha Multani, Pranathi M, Deepak Madi, Unnikrishnan B, John T Ramapuram, Satish Rao. Knowledge, Risk perceptions and attitudes of Nurses towards HIV in a tertiary care hospital in Mangalore, India. ID: JCDR. 2012. August vol(6), 982-986.

10. Rahul Magazine, Bharti Chogtu, Muthukumaran L, Nimisha Srivastava, Saisree Reddy A J. Knowledge, attitude and practice of nurses regarding HIV/AIDS in a tertiary care hospital. Pulmon, Vol. 14, Issue 1, JanApr 2012

11. Shyama Prasad Mitra, Sarmila Mallik, Madhabi Das, Amal Sinha Roy. Injection safety: Perception and practice of nursing students in tertiary setting. Indian J. Prev. Soc. Med. Vol. 41 No.3 and 4, 2010. ISSN : 0301-1216.

12. Rakhshan Shaheen Najmi, Department of Obstetrics and Gynaecology, Fatima Jinnah Medical College, Lahore. Awareness of Health Care Personnel about Preventive Aspects of HIV Infection/AIDS and their Practices and Attitudes Concerning such Patients. JPMA. December 1998. 367-370.

13. Yogindra Samant, Ranjit Mankeshwar, Lalit Sankhe, David L Parker. HIV-Related Knowledge and Attitudes among First Year Medical Students in
Mumbai, India. International Electronic Journal of Health Education, 2006; 9:13-24

14. Christina Ouzouni 1, Konstantinos Nakakis. HIV / AIDS knowledge, attitudes and behaviours of student nurses. Health science Journal. Volume 6, Issue 1 (January - March 2012)

15. Hassan ZM, Wahsheh MA. Knowledge and attitudes of Jordanian nurses towards patients with HIV/AIDS: findings from a nationwide survey.Issues Ment Health Nurs 2011; 32(12): 774-84.

16. Datta C, Bandyopadhyay D. Knowledge and attitudes in relation to HIV/AIDS among the in-service nurses of Calcutta. J Indian Med Assoc 1997; 95 : 75-7.

17. Lal P, Kumar A, Ingle GK, Gulati N. Some AIDSrelated policy issues and the nursing students' willingness to provide AIDS care. J Commun Dis $1998 ; 30: 38-43$.

18. Chen et al. Nurses' Knowledge, Attitudes, and Practice Related to HIV Transmission in Northeastern China. AIDS Patient Care STDS, Author manuscript; available in PMC 2013 March 03.2004 July ; 18(7): 417-422. doi:10.1089/1087291041518247.

19. Misbahuddin Mohammad, Farida Ahmad, Syed Z Rahman, Varun Gupta and Tariq Salman. Knowledge, Attitudes and Practices of Bioethics among Doctors in a Tertiary Care Government Teaching Hospital in India. Journal of clinical research and Bioethics. ISSN: 2155-9627.

20. Ravi Shankar1, Sanjay Pandey3, Sadhana Awasthi4 \& CMS Rawat. Awareness of HIV/AIDS among first year medical undergraduates in Nainital, Uttarakhand, India. Indian J. Prev. Soc. Med. Vol. 42 No.2, 2011.

21. Ruta Lukianskyte1, Julija Gataeva, Laimute Radziunaite. Needle sticks and sharps injuries experienced by staff nurses and nursing students and their prevention. doi: 10.3396/ijic.v8i1.002.12

22. Shalini Bharat. A systematic review of HIV/AIDSrelated stigma and discrimination in India: Current understanding and future needs. Journal of Social Aspects of HIV/AIDS Vol. 8. NO. 3 September 2011. 